\title{
Seismic Behavior of Flat Slab Buildings of Varied Heights Considering P-Delta Effect
}

\author{
Murnal Ashwini \\ Post-graduate student, Civil Engineering \\ Department, JNEC, Aurangabad \\ Aurangabad, Maharashtra
}

\author{
Kallurkar L.G. \\ Associate Professor, Civil Engineering \\ Department, JNEC, Aurangabad \\ Aurangabad, Maharashtra
}

\begin{abstract}
Flat slab structures are becoming quite popular due to functional and architectural advantages. They are typically used for small to medium rise buildings. The seismic behavior of a flat-slab structure needs special attention due to its flexible behavior and large lateral displacements. The secondary effects like P-delta assume significance due to large displacements. The behavior is governed by the plan aspect ratio and number of storeys in the building. This paper examines the effect of P-delta on seismic behavior of flat slab buildings with different aspect ratios and single to six storey rectangular buildings through performance based approach.
\end{abstract}

Key words- Performance based design, P-delta effect, flat slab buildings

\section{INTRODUCTION}

Flat slab construction is one of the popular type of construction due to its ease and speed of construction, architectural and functional features, etc. The lateral stiffness of the structure comprising of flat slab and column is much less than the slab-beam column construction which results in significant bending moments and shears due to horizontal loads that cannot be effectively transferred. During large deformations the becomes significant.

Many researchers have significantly contributed analytically and experimentally in the seismic behavior of flat slab structures [1], [6], [7], [9], [10]. Significant work is also found in literature regarding P-Delta effect on structures [2], [3], [4], [5], [8]. The effect of P-delta on 3storeyed flat slab building has been studied [11]. With the post-tensioned flat slab construction becoming quite popular it is necessary to study the behavior of such structures under seismic loading.

In this paper analytical investigations have been carried out to examine the seismic behavior of flat slab buildings with different plan aspect ratios and number of storeys considering P-delta effect using performance design approach.

\section{SYSTEM FORMULATION}

Under normal vertical loads, the structure may be subjected to lateral sway due to unsymmetry in structure or/and loads. During the sway the axial loads on the columns create additional moment and shears in the columns. This effect of axial loads during sway is referred to as P-delta effect. This effect is normally secondary in nature and hence is neglected.

In structures subjected to lateral earthquake loads the sway secondary effects may be quite significant which may govern the inelastic behavior under seismic loads.

The susceptibility of flat slab structures to severe damage during strong earthquakes is well documented. However the secondary effects due to large deformations are usually neglected in the analysis as many times the seismic forces are resisted by elements other than the columns, like shear walls. But the safety of such columns during large deformations may be questionable due to the secondary effects. These secondary effects for members can be quantified through the use of P-Delta analysis. According to IS 1893 "a flat-slab building in which lateral load resistance is provided by shear walls, since the lateral load resistance of the slab-column system is small, these are often designed mainly for the gravity loads, while all the seismic force is resisted by the shear walls. Even though the slabs and columns are not required to share the lateral forces, these deform with rest of the structure under seismic force. The concern is that under such deformations, the slab-column system should not lose its vertical load capacity." Thus the behavior of flat slab structure considering the secondary effects

would be significant. It is especially true when the structure is subjected to design earthquake forces in which case the lateral displacements are quite significant. If the structure is laterally flexible, as in the case of a flat slab buildings, this effect could be so significant that it may induce moments and shears comparable with primary forces and may lead to premature failures if not accounted appropriately in the analysis and design.

The P-Delta effect can be explained using a SDOF oscillator as shown in Fig.1. It is seen from the figure that due to the lateral load $\mathrm{V}$ the structure deforms in the lateral direction. If P-delta effect is not considered and the flexural behavior is assumed bi-linear the load-deflection curve will be as shown with solid line in Fig. 2. The lateral stiffness reduces at a yield force of $\mathrm{V}_{\mathrm{y}}$ and continues to deform till failure. If P-delta effect is considered the effect of vertical load $\mathrm{P}$ needs to be included in the formulation. Then there will be additional moment of $\mathrm{P} \delta$, in addition to $\mathrm{Vh}$ will be included which results in a behavior as indicated by dotted line (a) in Fig. 2. Effectively the structure is subjected to a moment of $\mathrm{Vh}+\mathrm{P} \delta$ and a shear of $\mathrm{V}+\mathrm{P} \delta / \mathrm{h}$. As a result the structure now yields at a lower $\mathrm{V}$ and higher reduction in stiffness after yield. The basic objective of this work is to examine the effect of P-delta phenomenon on performance 
of symmetrical flat slab buildings of varied number of storeys under seismic loading.

In the present work it is attempted to achieve the above objective through analytical studies on flat slab building models through performance based design approach. Pushover analysis is carried out to understand the nonlinear behavior and identify the performance levels. Further P-delta effect is included in the analysis to obtain the pushover curve. While considering the P-delta effect the structure is assumed as a SDOF isolator and accordingly the reduction in stiffness in pre-yield and post-yield is estimated. This is justified as the considered buildings are symmetrical and will have major mass participation in the first mode.

\section{EXAMPLE STRUCTURES}

Example structures considered in this work are symmetrical building models with varied plan dimensions and number of storeys. The plans are rectangular with different aspect ratios. Aspect ratios are defined as the ratio of plan dimension along the direction of applied load to the perpendicular plan dimension. One of the plan dimension is fixed as $16 \mathrm{~m}$ with two bays of $8 \mathrm{~m}$ each. The other dimension is varied from $12 \mathrm{~m}$ to $30 \mathrm{~m}$ with multiple bays of $6 \mathrm{~m}$ each. The resulting aspect ratios are $0.75,1.125,1.5$ and 1.875 . The floor heights are taken as $4.5 \mathrm{~m}$ for the first storey and $3 \mathrm{~m}$ for higher storeys. Buildings with single storey to six storey buildings are considered for the study. Usually in a flat slab building the seismic forces are taken by members other than those resisting gravity loads. However they are required to take the gravity loads successfully under large displacements during seismic loads. The member dimensions are selected so as to carry the gravity loads successfully. Therefore dimensions of the columns vary from $0.3 \mathrm{~m} \times 0.3 \mathrm{~m}$ for single storey building to $0.3 \mathrm{~m} \times 0.5 \mathrm{~m}$ for six storeyed buildings to take gravity loads safely. The slab thickness is taken as $250 \mathrm{~mm}$ and carry a live load of $3 \mathrm{kN} / \mathrm{m}^{2}$. The concrete used is of M25 and steel of Fe 415 grade. The modulus of elasticity of steel is assumed as $2 \times 10^{5} \mathrm{~N} / \mathrm{mm}^{2}$ and poisson's ratio of 0.3 is assumed.

The example structures are modeled in SAP-2000 commercial software. The structural elements, consisting of columns are directly supporting the slab without any pedestal near the joint. The joint between slab and column are assumed rigid. The flat slab is modeled using the strip method. The columns are assumed to be fixed at the foundation level. The infills are not considered in the modeling.

As the pushover analysis forms an important part of the analysis, the P-M2-M3 hinges are defined near the two ends of the columns, which means the columns will fail in combined axial load and biaxial bending. Default hinges as defined in the software are considered. The bilinear moment-curvature relationship is considered wherein the performance levels are defined in the post yield region.

\section{A. Pushover analysis}

The static pushover analysis is carried out on all the selected example buildings. The displacement based approach is adopted for the analysis. The load pattern applied is based on the first mode shape and is kept constant throughout the analysis. The target displacement is tentatively assumed as $1 \mathrm{~m}$ so that the behavior for large displacements is captured. The various hinge formations like IO, LS and CP as per the default hinge properties are captured in results. A plot of base shear vs roof displacement is plotted to get the pushover or capacity curve for each of the example structures.

4.4 Inclusion of P-Delta effect

The P-delta effect is included in the analysis by modifying the stiffness of the structure. For this purpose the behavior of the structure is simulated using a SDOF model behavior [2]. From the perspective of statics the P-delta effect can be visualized as an additional lateral loading that causes an increase in member forces and lateral deflections, reduces the lateral load resistance of the structure, and may cause a negative slope in the lateral load-displacement relationship at large displacements. For a bilinear single-degree-offreedom (SDOF) system of height $h$ the P-delta effect can be represented using a dimensionless parameter $\theta=P /(K h)$ (often called the stability coefficient) which describes the change in strength and stiffness. The elastic stiffness $K$ is reduced to $(1-\theta) K$, and the post-elastic stiffness $\alpha^{\prime} K$ is reduced to $\left(\alpha^{\prime}-\theta\right) K$. where $\alpha^{\prime}$ is the strain hardening ratio of the system without P-delta effects, and $\left(\alpha^{\prime}-\theta\right)$ is the ratio with P-delta effects, which is denoted here as the effective strain "hardening" ratio $\alpha$. If $\theta>\alpha$ ', then $\alpha$ becomes negative, and for such a case the system reaches a state of zero lateral resistance termed as "collapse".

From the above discussion it is clear that the reduction in elastic and post-yield stiffness will lead to minor reduction in lateral force (base shear) in the elastic phase for a specific lateral displacement. However this reduction in stiffness can be quite significant in the post-yield phase resulting in a negative stiffness because of the dominance of P-delta effect for large displacements. The negative stiffness results in a significant reduction in base shear for a given displacement and may reach zero base shear for relatively small displacements indicating collapse.

In the present work the above concept of SDOF system is adopted for the MDOF example structures. After obtaining the pushover curve without P-delta effect the reduction in base shear (or storey shear) for a given step of pushover having known lateral displacement (or storey drift) is estimated from $\mathrm{P} \delta / \mathrm{h}$, where $\mathrm{P}$ is the total vertical load or seismic weight of the structure (or total vertical load at the level under consideration), $\delta$ is the roof displacement (or storey drift) and $\mathrm{h}$ is the total height of the building (or storey height). This value is deducted from the known base shear (or storey shear) to get the reduced base shear V'. The graph of V' vs $\delta$ gives the pushover curve including the P-delta effect. Using this approach the effect of P-delta can be examined both at a global structural level or storey level.

4.5 Results and Discussion

The pushover curves as obtained from the analyses are plots of base shear vs roof displacement. However the comparative analysis cannot be done using directly these 
curves as the base shear is a function of the seismic weight of the building. Therefore it will be appropriate to normalize the base shear with the seismic weight of the building so that the comparison can be done between the various example structures considered. Further the roof displacement also is a relative parameter which may not be appropriate for comparison purpose. Therefore the normalized displacement is defined in percentage drift angle (percentage of roof displacement with respect to height of the building) so that the comparison is meaningful. Similarly the storey shears are normalized with respect to the total seismic weight and storey drifts are normalized with respect to storey height expressed in percentage.

The sample pushover curves of single storeyed and six storeyed buildings with and without P-delta effect are shown in Fig. 3 and Fig. 4 respectively. From these figures it is observed that there is a significant reduction in base shear values for the models with P-delta effect for a given displacement. There is a significant difference in the behavior of single storey and six storey buildings. The single storey buildings go into negative stiffness after reaching maximum base shear whereas six storeyed buildings suddenly undergo a brittle failure at the maximum base shear. It is also seen that the strain hardening observed in buildings without P-delta effect is not found when P-delta effect is considered.

Table 1, (a) to (d) give variation of base shear ratios at onset of collapse with increase in number of stories and reduction in these ratios due to P-delta effect for various aspect ratios. From these tables it is observed that the base shear ratios decrease with increase in number of stories. An increase in base shear ratio is observed for five storey building which further decreases for six storey structures. This is because of higher size columns chosen for five storey and above buildings. As the number of storeys increase, the reduction in resistance at the onset of collapse hinges increases, which means the effect P-delta increases with increase in number of storeys. It is also observed that as the number of storeys increase the \% drift angle at which the collapse hinges start forming decreases, which again confirms the higher P-delta effect for taller structures. The effect of number of storeys is not significant for higher aspect ratios.

TABLE 1. BASE SHEAR RATIOS AT ONSET OF COLLAPSE HINGES WITH INCREASE IN NUMBER OF STOREYS FOR DIFFERENT ASPECT

(a) Aspect ratio: 0.875

\begin{tabular}{|l|rr|r|r|r|}
\hline Building & $\begin{array}{c}\text { Base shear } \\
\text { without } \\
\text { effect }\end{array}$ & $\begin{array}{c}\text { ratio } \\
\text { P-delta }\end{array}$ & $\begin{array}{c}\text { Base Shear ratio with } \\
\text { P-delta effect }\end{array}$ & $\begin{array}{c}\text { \% reduction due to } \\
\text { P-delta effect }\end{array}$ & \% top storey drift \\
\hline Single-storeyed & & 0.554 & 0.516 & 6.875 & 3.810 \\
\hline Two-storeyed & 0.270 & 0.244 & 9.629 & 1.596 \\
\hline Three-storeyed & 0.172 & 0.152 & 1.528 & 1.983 \\
\hline Four-storeyed & 0.078 & 0.065 & 17.217 & 1.237 \\
\hline Five-storeyed & 0.094 & 0.081 & 18.228 & 1.066 \\
\hline Six-storeyed & 0.059 & 0.048 & & 184 \\
\hline
\end{tabular}

(b)

\begin{tabular}{|l|r|r|r|r|r|}
\hline Aspect ratio: 1.125 & $\begin{array}{c}\text { Base shear } \\
\text { without } \\
\text { effect }\end{array}$ & $\begin{array}{c}\text { ratio } \\
\text { P-delta }\end{array}$ & $\begin{array}{c}\text { Base Shear ratio with } \\
\text { P-delta effect }\end{array}$ & $\begin{array}{c}\text { \% reduction due to } \\
\text { P-delta effect }\end{array}$ & $\%$ top storey drift \\
\hline Single-storeyed & 0.488 & 0.450 & 7.627 & 3.719 \\
\hline Two-storeyed & 0.241 & 0.215 & 10.627 & 1.562 \\
\hline Three-storeyed & 0.158 & 0.138 & 12.600 & 1.995 \\
\hline Four-storeyed & 0.104 & 0.090 & 13.595 & \\
\hline Five-storeyed & 0.114 & 0.101 & 11.635 & 1.326 \\
\hline Six-storeyed & 0.086 & 0.074 & 14.942 & \\
\hline
\end{tabular}

\begin{tabular}{|l|rr|r|r|r|}
\hline Building & $\begin{array}{c}\text { Base shear } \\
\text { without } \\
\text { effect }\end{array}$ & $\begin{array}{r}\text { ratio } \\
\text { P-delta }\end{array}$ & $\begin{array}{c}\text { Base Shear ratio with } \\
\text { P-delta effect }\end{array}$ & $\begin{array}{c}\text { \% reduction due to } \\
\text { P-delta effect }\end{array}$ & \% top storey drift \\
\hline Single-storeyed & 0.333 & 0.293 & 12.041 & 4.006 \\
\hline Two-storeyed & 0.163 & 0.137 & 16.134 & 1.634 \\
\hline Three-storeyed & 0.150 & 0.130 & 13.180 & 1.432 \\
\hline Four-storeyed & 0.114 & 0.099 & 12.601 & 1.632 \\
\hline Five-storeyed & 0.195 & 0.178 & 8.390 & 1.217 \\
\hline Six-storeyed & 0.088 & 0.076 & 13.878 & \\
\hline
\end{tabular}

(d)

\begin{tabular}{|l|rr|r|r|r|}
\hline Building & $\begin{array}{c}\text { Base } \\
\text { without } \\
\text { effect }\end{array}$ & $\begin{array}{r}\text { ratio } \\
\text { P-delta }\end{array}$ & $\begin{array}{c}\text { Base Shear ratio with } \\
\text { P-delta effect }\end{array}$ & $\begin{array}{l}\text { \% reduction due to } \\
\text { P-delta effect }\end{array}$ & \% top storey drift \\
\hline Single-storeyed & 0.320 & 0.280 & 12.523 & 4.008 \\
\hline Two-storeyed & 0.157 & 0.131 & 16.749 & 2.628 \\
\hline Three-storeyed & 0.095 & 0.078 & 18.022 & 1.714 \\
\hline Four-storeyed & 0.110 & 0.096 & 12.924 & 1.421 \\
\hline Five-storeyed & 0.169 & 0.148 & 12.583 & 2.128 \\
\hline Six-storeyed & 0.079 & 0.066 & 15.734 & 1.238 \\
\hline
\end{tabular}




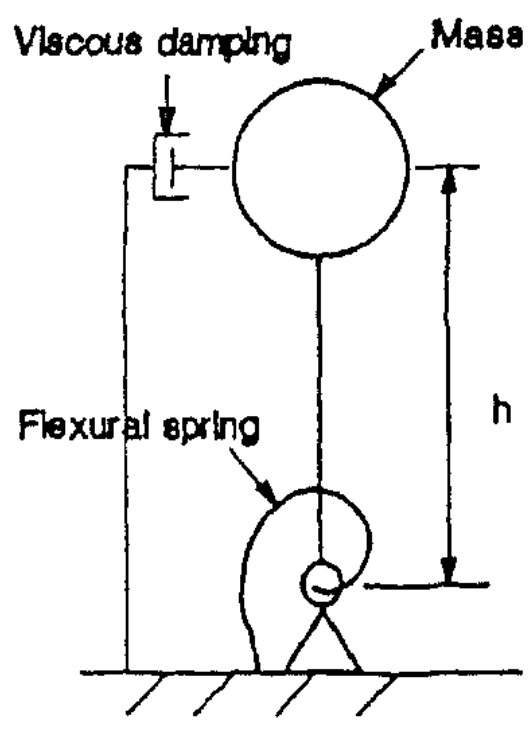

MODEL.

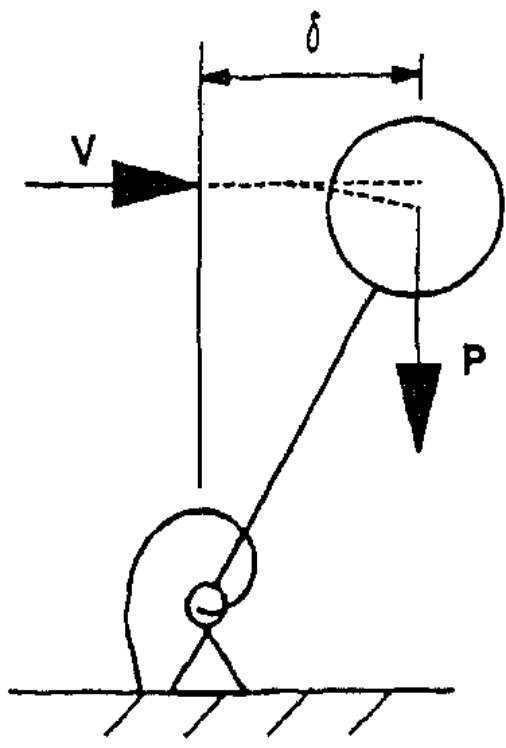

DERLECTED SHAPE

Fig. 1 Schematic representation of P-Delta effect on a SDOF oscillator

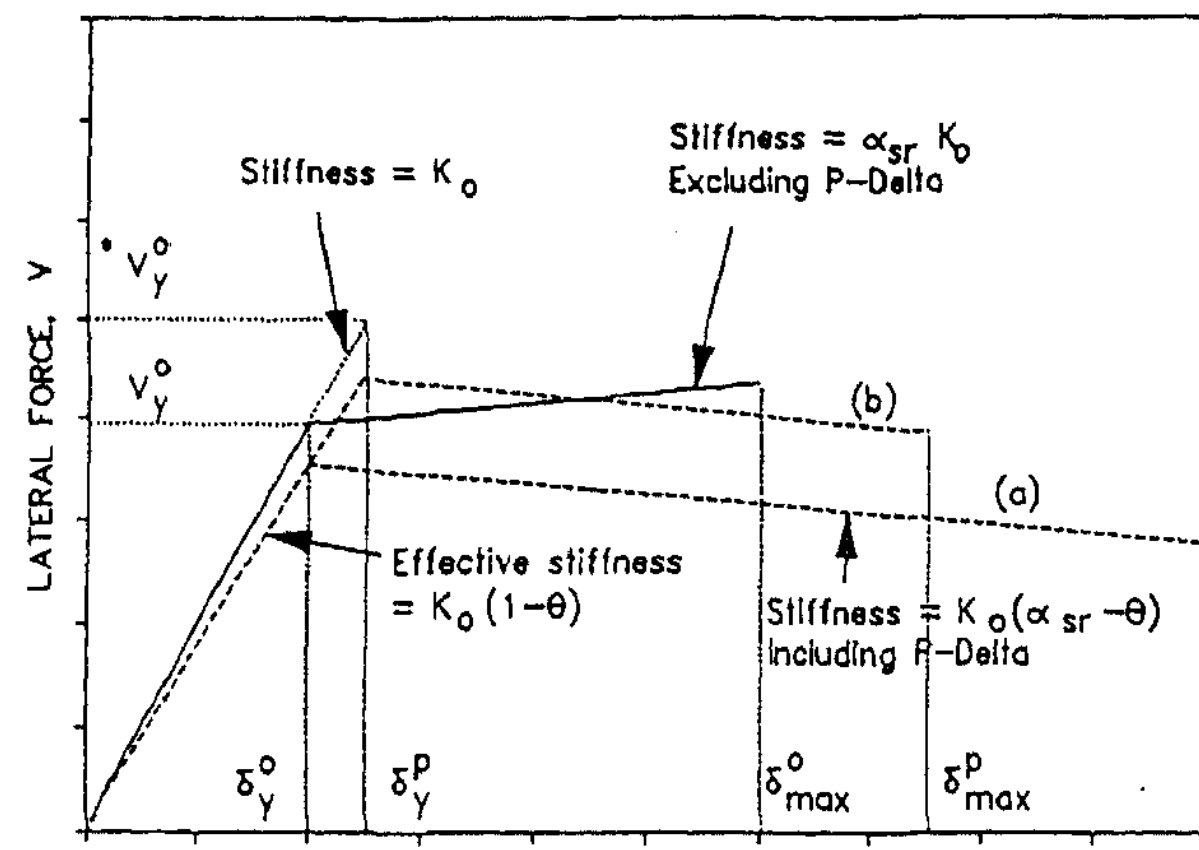

LATERAL DEFLECTION, $\delta$

Fig. 2 Force-deformation behavior of SDOF oscillator with and without P-delta effect. 


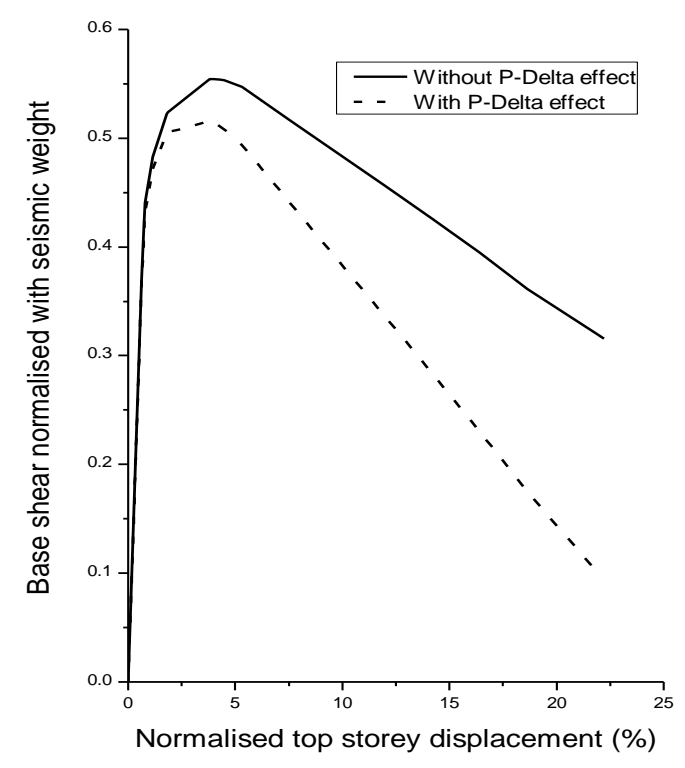

(a) Aspect ratio $=0.75$

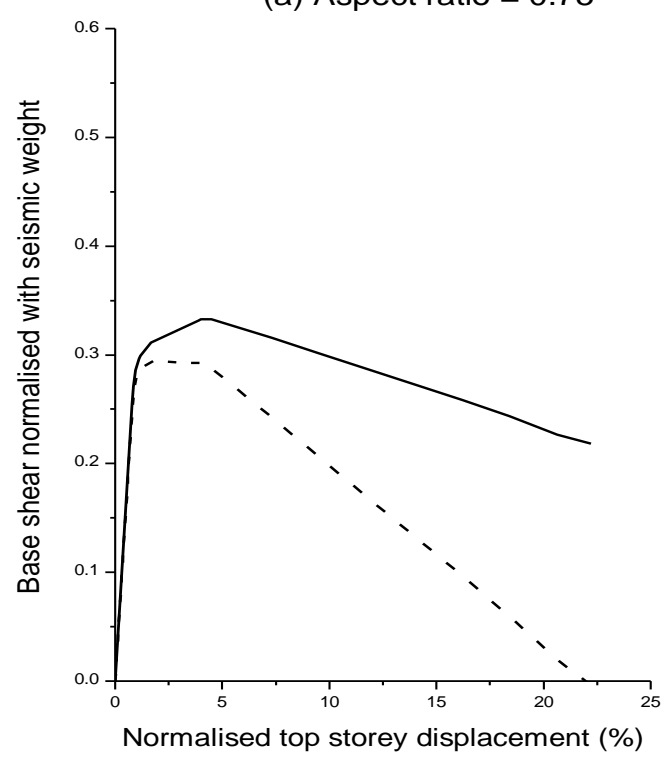

(c) Aspect ratio $=1.5$

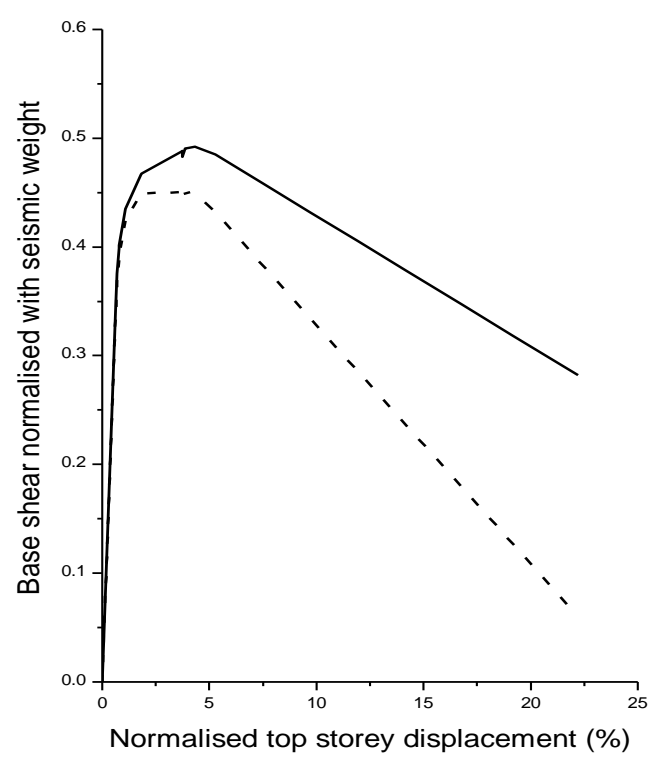

(b) Aspect ratio $=1.125$

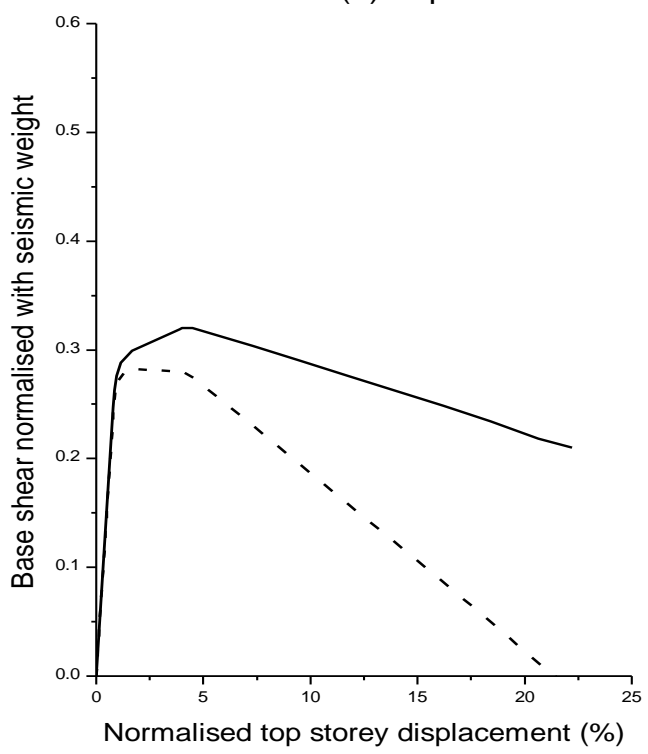

(d) Aspect ratio $=1.875$

Fig. 3 P-delta effect on single storey buildings with different aspect ratios 


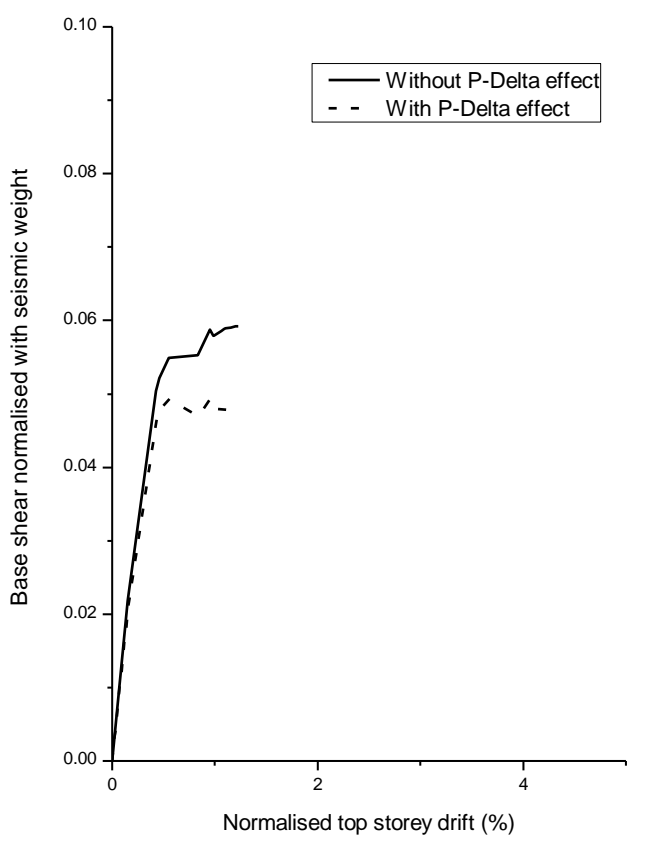

(a) Aspect ratio $=0.875$

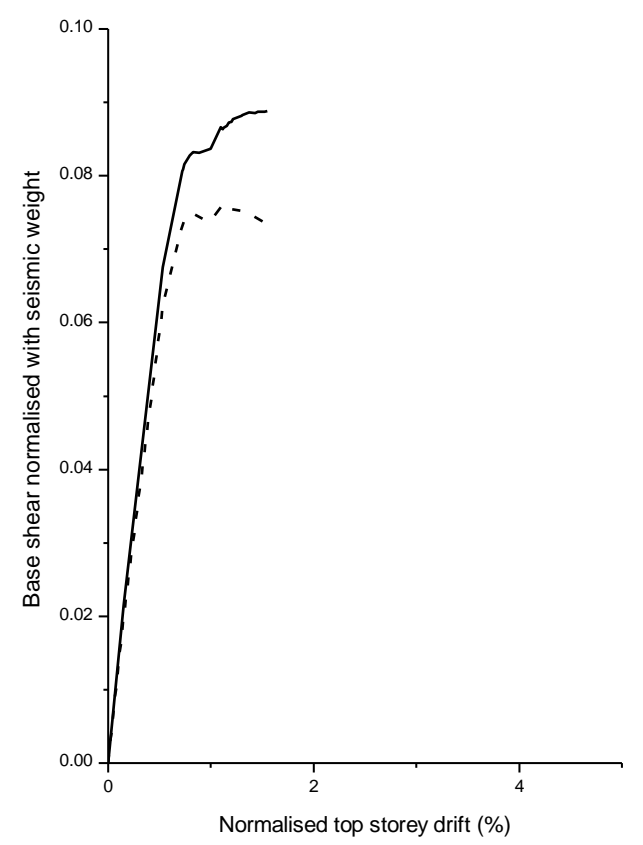

(c) Aspect ratio $=1.5$

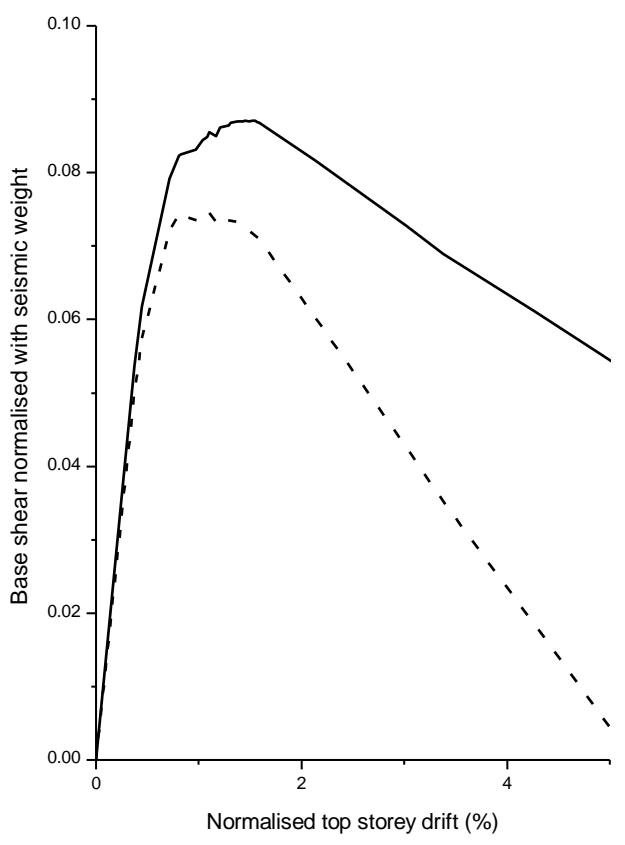

(b) Aspect ratio $=1.125$

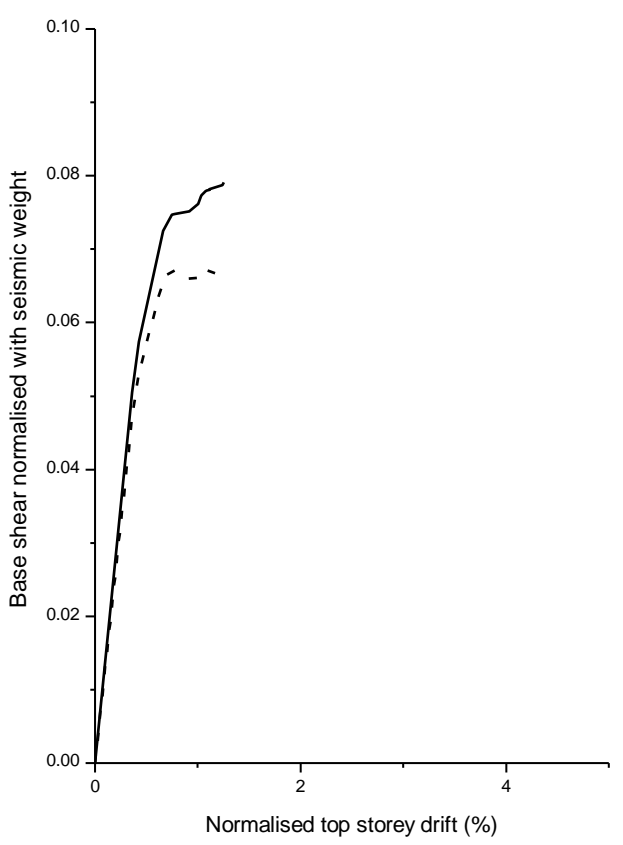

(d) Aspect ratio $=1.875$

Fig. 4. P-delta effect on six storey buildings with different aspect ratios 


\section{CONCLUSIONS}

The effect of P-delta on seismic behavior of flat slab buildings is studied through analytical investigation in this paper. Based on the work following conclusions are drawn.

1. The post-yield behavior of flat slab structures under lateral loading is significantly different if P-delta effect is included.

2. The ultimate capacity of a flat slab structure is significantly over-estimated if P-delta effects are neglected.

3. The failure pattern for buildings with higher number of storeys is brittle.

4. As the number of storeys increase, the reduction in resistance at the onset of collapse hinges increases, which means the effect Pdelta increases with increase in number of storeys.

\section{REFERENCES}

[1] Ahmad J. Durrani, S. T. Mau, Amr Ahmed AbouHashish and $\mathrm{Yi} \mathrm{Li}$, ."Earthquake Response of Flat-Slab Buildings." , ASCE J. Struct. Eng., DBB, 1994, 947-954.

[2] Akshay Gupta and Helmut Krawinkler, . "Dynamic P-Delta effects for flexible inelastic steel structures.", ASCE $J$. Struct. Eng., DG(1) 2000, 145-154.

[3] Davidson B.J., Fenwick R.C., and Chung B.T., "P-Delta effects in multi-storey structural design.", Tenth World Conference on Earthquake Engineering, Balkema, Roterdam, 1992 3847-3852.

[4] H. Scholz, "P-Delta effect in elastic analysis of Sway Frames" ASCE J. Struct. Eng., 1133, 1987, 534-545.

[5] H. Scholz, "P-Delta effect under repeated Loading" ASCE J. Struct. Eng., 1168, 1990, 2070-2082.

[6] Kai Qian and Bing Li, "Strengthening of Multibay Reinforced Concrete Flat Slabs to Mitigate Progressive Collapse" ASCE J. Struct. Eng., 141(6, 2015, 04014154-1-13.

[7] Leila Keyvani, and Mehrdad Sasani, "Analytical and Experimental Evaluation of Progressive Collapse Resistance of a Flat-Slab Posttensioned Parking Garage ASCE J. Struct. Eng., 11(11) 2015, 04015030-1-8.

[8] Regina Gaiotti, and Bryan Stafford Smith, "P-Delta analyis of building structures." ASCE J. Struct. Eng., 115(4, 1989, 755-770.

[9] Somaprasad R. Hosahalli, and Ahmet E. Aktan, "Seismic Vulnerability of Flat Slab-Core Buildings" ASCE J. Struct. Eng., 102, 1994, 339-359.

[10] Sang-Whan Han, Young-Mi Park, and Seong-Hoon Kee, "Stiffness Reduction Factor for Flat Slab Structures under Lateral Loads" ASCE J. Struct. Eng., 135(6), 2009, 743750 .

[11] Murnal Ashwini and Shinde Sangeeta. "Seismic performance of flat slab buildings considering P-delta effect" Journal of Structural Engineering and Management, 2020, 7(1), pp 10-16. 